\title{
Numerical and in-situ investigation on the ground behavior of the end roof in fully mechanized caving face
}

\author{
Chuanwei Zang ${ }^{1}$, Miao Chen $^{1 *}$, Yang Chen ${ }^{1}$, Xuean Zhuang ${ }^{2}$, Chenming Zhai ${ }^{1}$, and \\ Hongmo $\mathrm{Zhu}^{1}$ \\ ${ }^{1}$ College of Energy and Mining Engineering, Shandong University of Science and Technology, \\ Qingdao 266590, China \\ ${ }^{2}$ China Coal Technology Engineering Group Chongqing Research Institute, Chongqing 400037, \\ China
}

\begin{abstract}
Fully mechanized top coal caving is a major high-yield and high-efficiency coal mining method for thick seam mining. At present, it is affected by the further popularization and application of fully mechanized caving mining because the recovery rate is limited. The research on the technology of fully mechanized top coal caving and transitional coal mining is crucial. This paper aims at the top coal recovery with the top coal of the fully mechanized caving face and the transitional frame at both ends of the working face. With the top roof structure model of the fully mechanized caving face, the numerical simulation and field measurement is used to compare the end coal caving. With caving coal or not, the destruction and migration rules of the top coal in the fully mechanized caving face are obtained. The study found that at the end of the transport trough, the maximum concentration factor of the support pressure in the coal is 2.35 , and the maximum vertical displacement is $9.2 \mathrm{~cm}$. And at the end of the return air trough, the support pressure concentration factor is 3.53 , and the maximum vertical displacement of the roof is $102 \mathrm{~cm}$. The above research reveals the law of the occurrence of the pressure and the movement of the top coal when caving the coal at the end, while ensuring the safe production and efficient mining of the coal mine.
\end{abstract}

\section{Introduction}

Coal resources account for more than $55 \%$ of China's primary energy consumption. Coal supports the rapid development of China's economy. Even if a diverse structure of energy is formed in 2050, coal will still account for more than 40\% of China's energy structure [1-3]. At present, China has proven coal reserves of 900 billion tons, of which coal reserves in thick coal seams account for $44.1 \%$ and $45.6 \%$ of total coal production [4-5]. Therefore, how to ensure the safe and efficient mining of coal resources in thick coal seams has

${ }^{*}$ Corresponding author: miaochen@s,sdust.edu.cn 
become the key to solving China's energy problems. Fully mechanized mining has the advantages of high production efficiency, low energy and material consumption, low roadway excavation rate, low production cost, and strong adaptability to geological conditions. It gradually replaces layered comprehensive mining as the main technology for top coal mining. Mining wells have also entered a new period of development [6-8].

At the same time as the development of fully mechanized caving mining technology, theoretical research has also continued to deepen. The top coal and roof at the end of a fully mechanized caving face have the same lithology as the top coal and roof of a coal mining face, and its breaking characteristics and movement patterns are the same as those of the overlying strata during the mining of the upper working face and the working face in this section It is closely related to the laws of activities, but it has its own characteristics and laws [9-10]. According to the research, there is a macro stress shell composed of high stress bundles in the surrounding rock of the fully mechanized top coal caving face, which is closely related to the thickness of the coal seam at one time. The masonry beam structure is located in the decompression zone under the macro stress shell. The breakage and instability of the masonry beam structure will cause the phenomenon of periodic pressure on the working surface, but it will not generate a large dynamic pressure. Only the imbalance of the stress shell will cause severe The phenomenon of mine pressure [12]. The main mechanical field characteristic of the fully mechanized caving face is that it is located in the low stress area protected by the macro stress shell of the overlying strata. This is also the fundamental reason for the easing of the mine pressure in the fully mechanized caving face [13].

The above research has promoted the understanding of the overlying strata movement structure and the development of the theory of mineral pressure, and to some extent, it has reflected the roof movement characteristics. Surrounding the core issue of increasing the top coal release rate, it is generally believed that the appearance of the coal pressure in the fully mechanized top coal depends mainly on the structure of the overburden, the degree and stiffness of the top coal, the working parameters of the support and the mining and stress at the mining site Environmental factors [14-17]. Through the theoretical analysis and research of the top coal caving face and the comprehensive analysis of the observation results of many top coal caving faces, the top coal caving face also has the general law of the appearance of the coal mining face, that is, there is a periodic law of the appearance of the pressure. However, because it uses thicker coal seams as the roof, it also has the characteristics of the broken and soft roof [18]. Support working resistance is generally smaller than single coal seams and stratified mining faces under the same geological conditions and is generally $20 \%$ to $30 \%$ lower than ordinary working faces [19]. Due to the increase in the thickness of the coal seam at one time, the mining pressure of the roadway along the goaf is severe. Especially when the end-top coal mining is implemented, the influence range of the advanced support pressure on the working face is large, the deformation of the surrounding rock of the roadway is large, and the pressure of the roadway appears periodic [20,21].

At present, there are still some problems that need to be solved urgently in the mining of top coal, such as insufficient theoretical research on the pressure at the end of the fully mechanized caving face, and the relatively low recovery rate of the fully mechanized caving face. To sum up, at present, domestic and foreign countries have conducted in-depth and systematic research on the appearance pressure of fully mechanized caving mining face and roadway, the movement law of top coal, and the caving behavior of top coal. A series of explorations have been carried out, but there is still no systematic and in-depth study on the deformation and failure laws of the top coal at the end of the working face and the top coal above the headstock (transition support) and the characteristics of the top coal. Therefore, to further improve the resource recovery rate of the fully mechanized top coal caving face, it is of great significance to research and develop an efficient end-to-end coal caving support for in-situ coal mines, to study in-depth coal caving technology at the fully mechanized caving face, and to recover the top coal at the end. 


\section{Geological condition and monitoring scheme}

\subsection{Geological condition}

In this paper, No. 6202 fully mechanized caving face of Wangzhuang Mine in Lu'an Mining Area is used as the engineering prototype. The elevation of the working face is between 600 $\sim 622 \mathrm{~m}$, and the elevation of the ground is between $927 \sim 930 \mathrm{~m}$. As shown in Figure 1, No. 6202 working face is connected to No. 62 downhill track lanes and No. 62 downhill belt lanes in the north and No. 6216 tail gas lanes on the south side with No. 62 monkey vehicle laneing on the outside of the transport lanes. And the width of $18 \mathrm{~m}$ coal pillars lanes on the side of wind lanes. Outside the wind lanes is No. 6216 mined faces with $5 \mathrm{~m}$ coal pillars. The working lane length of the working face is $1567 \mathrm{~m}$, the length of the wind lane is $1538 \mathrm{~m}$, and the cut length of the working face is $248.5 \mathrm{~m}$, which as shown in Figure 2.

The No. 3 coal seam mined in the No. 6202 fully mechanized caving face is present in the strata of the Shanxi Formation of the Permian which is a continental lake-type sediment. The thickness of the coal seam is stable, with a total thickness of about $7.23 \mathrm{~m}$. The whole coal contains 5 layers of concrete, with the cumulative thickness $0.40 \mathrm{~m}$, and the inclination of the coal seams on both wings is between 1 and $4^{\circ}$. No. 6202 fully mechanized caving face uses inclined longwall comprehensive mechanized caving coal, with large mining height and low level caving coal technology to achieve full mining at one time. The height of the bottom mining layer is $3.6 \mathrm{~m}$, the cycle mining height is $0.8 \mathrm{~m}$, and the average thickness of the top layer is $3.23 \mathrm{~m}$. Shearer drum cut-off depth is $0.8 \mathrm{~m}$, and the moving frame step is $0.8 \mathrm{~m}$.

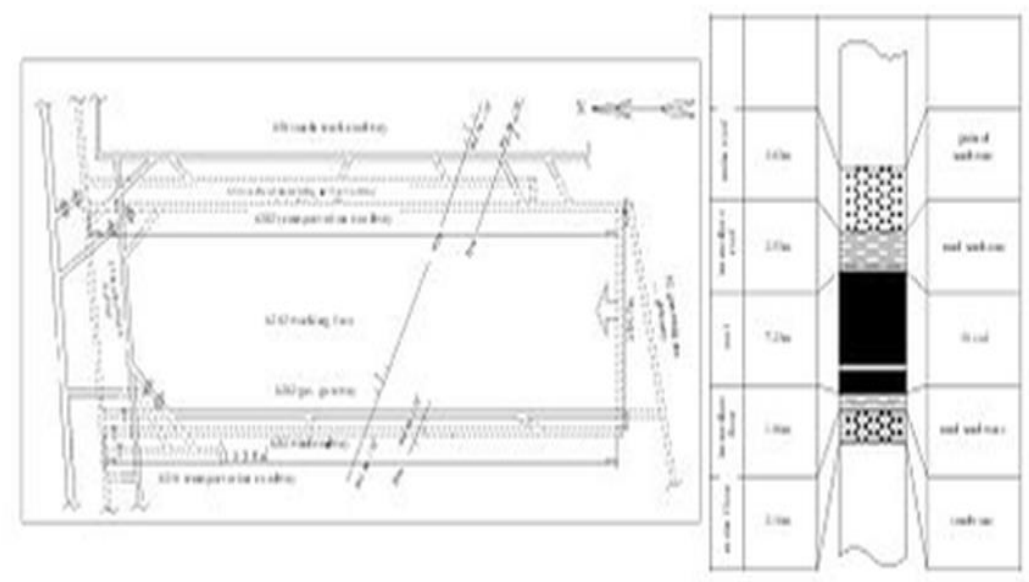

(a) Layout of No. 6202 mining face

(b) Geology columnar

Fig. 1. Layout of No. 6202 mining face and coal face 


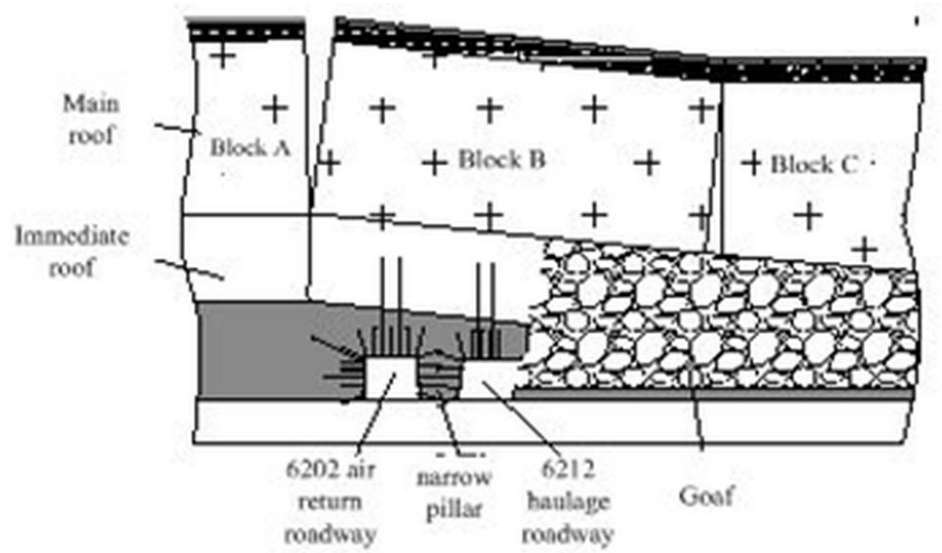

Fig. 2. Strata columnar section of No. 6202 mining face

\section{Numerical modelling}

Based on the site engineering geological conditions, a 3DEC numerical model was established, with a model depth of $\mathrm{H}=300 \mathrm{~m}$ and a size of. The model grid was divided into different sizes according to the research requirements, as shown in Figure 4. According to the calculation theory of the mechanical model, horizontal displacement constraints are set on the left and right boundaries of the model, that is, $\mathrm{ux}=0$, and the lower boundary is a fixed constraint, that is, $\mathrm{ux}=\mathrm{uy}=0$. The upper boundary is set as a stress boundary condition, and a vertical load of 7.3 MPa is applied. The phase analysis method for gradual mining is used for simulation analysis. The physical and mechanical parameters of the rock formation are listed in Table 1.

To compare and study the law of the occurrence of coal pressure under two conditions of end-top coal and no-top coal, a numerical model was established under the two conditions. The end-to-top coal mining scheme can be divided into tailing coal and tailing coal. Among them, tailing coal can be further divided into 3 \# tailing coal alone and $2 \sim 3$ \# tailing coal. $1 \sim 3$ \# tailstock rack cooperative coal deposit, headstock rack coal deposit can be further divided into 3 \# headstock rack separate coal, $2 \sim 3$ \# headstock rack cooperative coal, $1 \sim 3$ \# headstock rack cooperative coal.

Based on the site engineering geological conditions, a 3DEC numerical model is established, with a model depth of $\mathrm{H}=300 \mathrm{~m}$ and a cubic with length $40 \mathrm{~m}$, width $40 \mathrm{~m}$ and height $18 \mathrm{~m}$. The model grid is divided into different sizes according to the research requirements, as shown in Figure 3. According to the calculation theory of the mechanical model, horizontal displacement constraints are set on the left and right boundaries of the model, which means ux $=0$. And the lower boundary is a fixed constraint, which means ux $=\mathrm{uy}=0$. The upper boundary should be set as a stress boundary condition with a vertical load of 7.3 MPa applied. The phase analysis method for gradual mining is used for simulation analysis. The physical and mechanical parameters of the rock formation are listed in Table 1.

To compare and study the law of the occurrence of coal pressure under two conditions of end-top caving coal and no-top caving coal, the numerical models are established under the two conditions respectively. The end-to-top coal mining scheme can be divided into head caving coal and tailing caving coal. Among them, tailing coal can be further divided into No.3 \# tailing coal alone and No. 2, No. 3 \# tailing coal cooperatively. No. 1, No. 2, and No. 3 \# tailstock rack coal cooperatively. And headstock rack caving coal can be further divided into No. 3 \# headstock rack separate coal, No 2, No. 3 \# headstock rack caving coal cooperatively, No. 1, No. 2, No. 3 \# headstock rack caving coal cooperatively. 


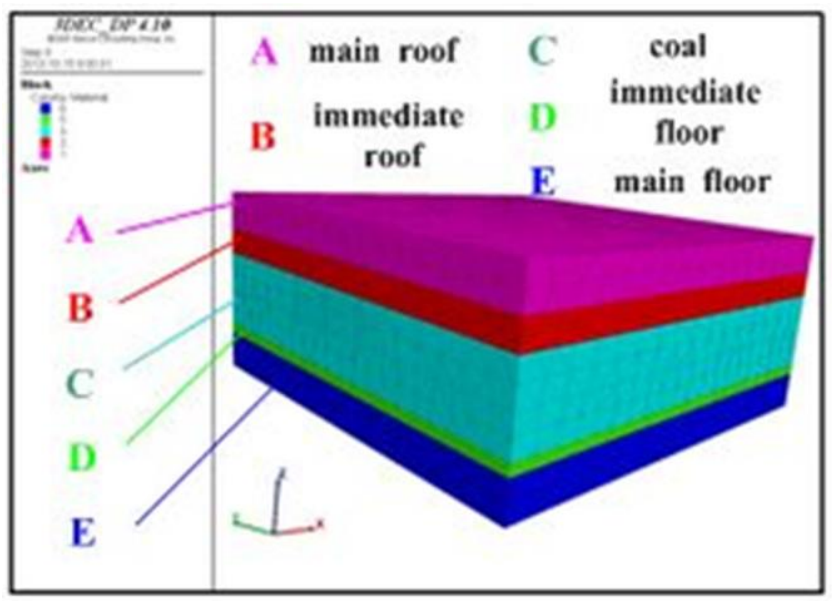

Fig. 3. Numerical model

Table 1. Mechanical parameters of rock strata

\begin{tabular}{|c|c|c|c|c|c|c|c|}
\hline Lithology & $\begin{array}{c}\text { Thicknes } \\
\mathbf{s} / \mathbf{m}\end{array}$ & $\begin{array}{c}\text { Density// } \\
\mathbf{t} \cdot \mathbf{m}^{-3}\end{array}$ & $\begin{array}{c}\text { Bulk } \\
\text { modulus/ } \\
\mathbf{G P a}\end{array}$ & $\begin{array}{c}\text { Shear } \\
\text { modulus/ } \\
\mathbf{G P a}\end{array}$ & $\begin{array}{c}\text { Cohesi } \\
\text { on } \\
\text { /MPa }\end{array}$ & $\begin{array}{c}\text { Interna } \\
\mathbf{l} \\
\mathbf{f r i c t i o n} \\
\text { angle/ }\end{array}$ & $\begin{array}{c}\text { Tensile } \\
\text { strength/ } \\
\text { MPa }\end{array}$ \\
\hline $\begin{array}{c}\text { Find } \\
\text { sandstone }\end{array}$ & 3.60 & 2.60 & 60 & 55 & 2.5 & 45 & 5.8 \\
\hline Mudstone & 2.5 & 2.40 & 55 & 55 & 2.5 & 40 & 2.2 \\
\hline Top-coal & 3.8 & 1.35 & 40 & 35 & 1.5 & 35 & 1.4 \\
\hline Coal seam & 3.5 & 1.35 & 40 & 35 & 1.5 & 35 & 1.4 \\
\hline Mudstone & 1.03 & 2.40 & 55 & 55 & 2.5 & 40 & 2.2 \\
\hline $\begin{array}{c}\text { Medium } \\
\text { sandstone }\end{array}$ & 3.57 & 2.50 & 60 & 60 & 3 & 55 & 5.8 \\
\hline
\end{tabular}

\section{Numerical simulation results and analysis}

\subsection{Top coal non-caving}

No. 6202 working face has a height of $7.3 \mathrm{~m}$ and a coal pillar width of $5 \mathrm{~m}$ between the goaf of No. 6216. The 6202 working face return airway is $3.2 \mathrm{~m}$ high, the transportation lane is $3.5 \mathrm{~m}$ high, and the width is $5 \mathrm{~m}$. After building the modeling, excavation and support of the working face and the mining roadway are performed first, and the calculation of the end is performed to a balanced state. The transition frame of the working face is not allowed to mine coal, and the model after the excavation is shown in Figure 4. According to Figure 4, it is found that after the working face is pushed over, due to the existence of the return air lane which is near the goaf and the existence of coal pillars, the roof structure at the end of the return air lane formed a "arch-like" collapse in the goaf. Due to the end of the track roadway is near to the solid-coal support, a typical "masonry beam" structure is formed laterally in the goaf of the working face. 


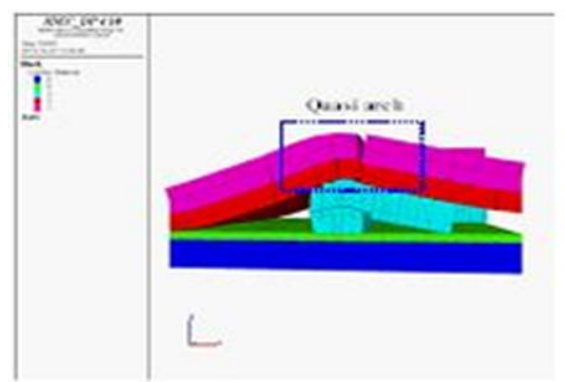

(a) Headgate

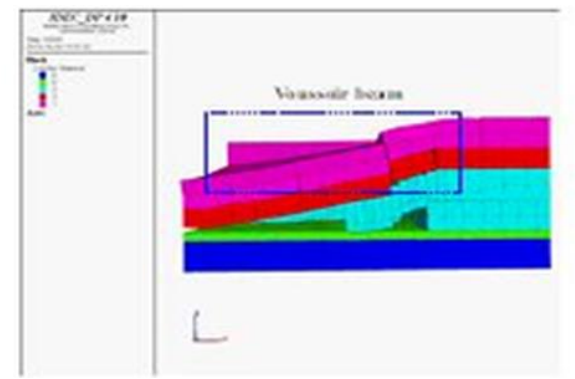

(b) Tailgate

Fig. 4. End roof structures of headgate and tailgate with top coal non-caving

At both ends of the roof, hinged structures are basically formed, and the broken block rotates along the hinge point (Figure 5); a certain degree of stress concentration occurs in the top coal (Figure 6); some deformation of the surrounding rock occurs, and the top coal is mostly in plastic failure, which is conducive to the top coal caving naturally.

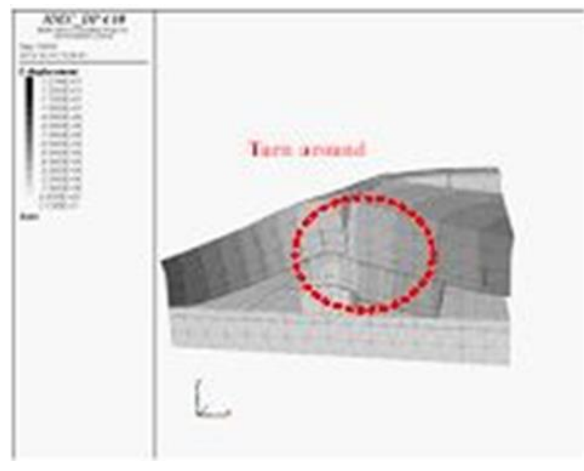

(a) Headgate

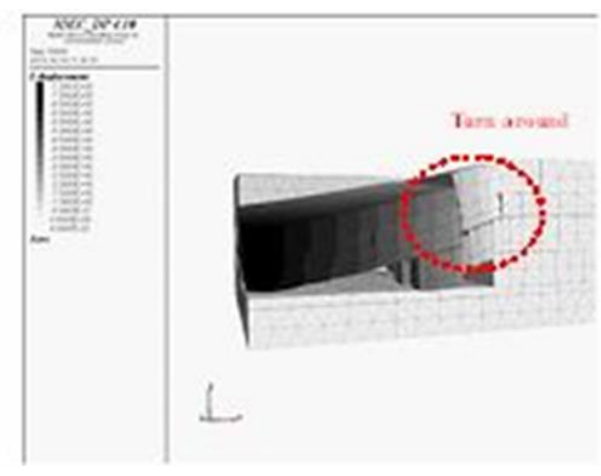

(b) Tailgate

Fig. 5. Surrounding rock displacement of headgate and tailgate with top coal non-caving

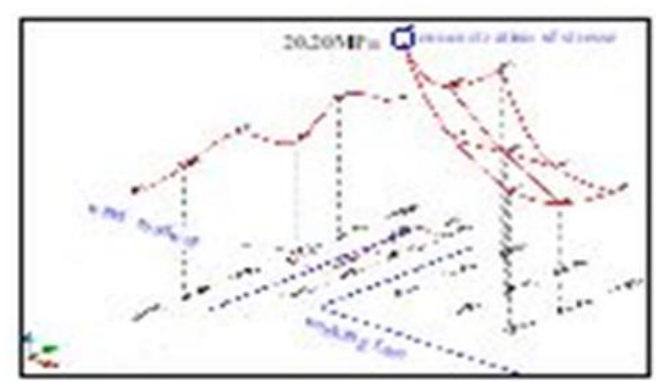

(a) Headgate

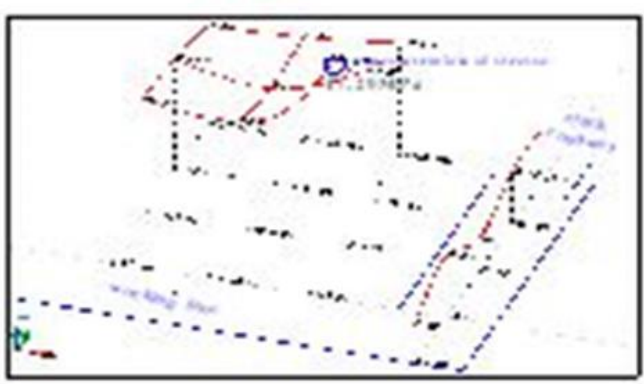

(b) Tailgate

Fig. 6. Stress distribution of headgate and tailgate with top coal non-caving

Pressure monitoring shows that the pressure at the end of the return airway is mainly concentrated at the intersection of the roadway and the working face. The vertical stress in the coal pillar at the end section is $14.5 \mathrm{MPa}$. The maximum in solid coal of the intersection between working face and trough pressure is up to $26.29 \mathrm{MPa}$, and the stress concentration factor is 3.37. The maximum position movement of the roof near the end occurs at the intersection of the working face and the trough. The maximum roof movement of the end of 
the return airway is $1.02 \mathrm{~m}$. Figure 6 (a) shows the stress distribution at the intersection between the transport slot and the working face. The maximum stress point is located in the solid coal at the intersection between the work face and the slot with the max pressure value $18 \mathrm{MPa}$. And the stress concentration factor is 3.37. The maximum roof movement of the roof is $0.092 \mathrm{~m}$.

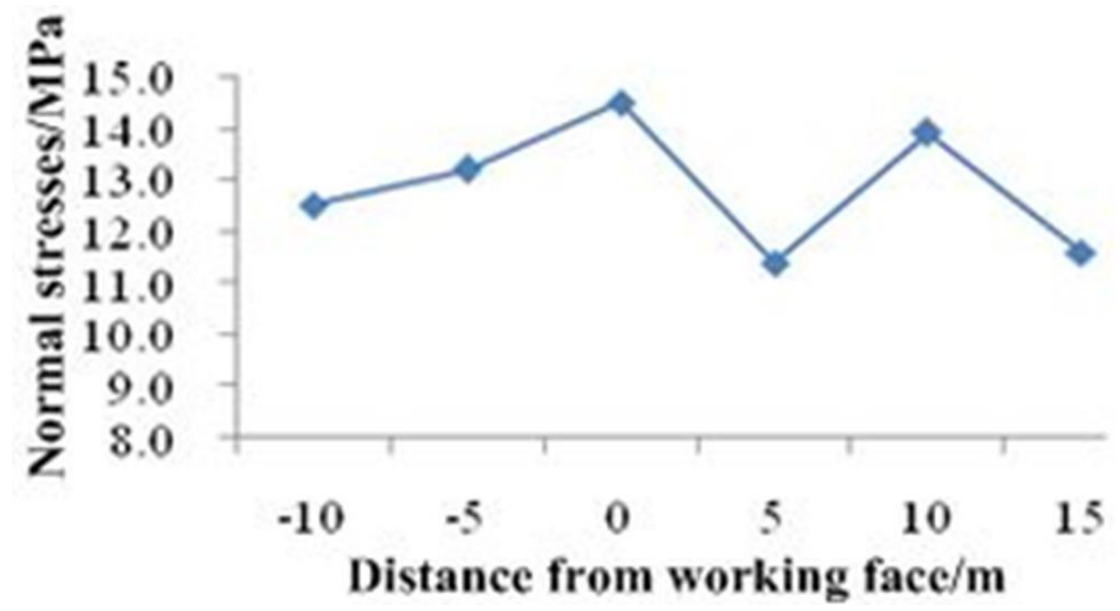

Fig. 7. Vertical stress evolution of coal pillar

As shown in Figure 8, the vertical stress in the coal pillar in the section within $30 \mathrm{~m}$ of the advance direction is wavy forward, with a period of about $10 \mathrm{~m}$, which indicates that the coal pillar and the trough roof were already mined when the upper section was mined. A periodic fracture occurs due to supporting pressure, and at the same time, the pressure value behind the working surface tends to be stable.

\subsection{Top coal caving}

\subsubsection{Impact of headstock placement on the tip area}

\section{(1) No. 3 \# headstock}

The displacement of the top plate in the tip area and the vertical stress distribution are shown in Figure 8. A "masonry beam" hinge structure is formed on the basic roof, and the broken block rotates along with the hinge point. Stress concentration occurs in the top coal to some extent, and the highest stress concentration is located within $5 \mathrm{~m}$ of the solid coal side of the working face and the corner of the return air lane. The value of the concentration factor is 2.35 and the maximum displacement of the roof at the corner is $0.089 \mathrm{~m}$. 


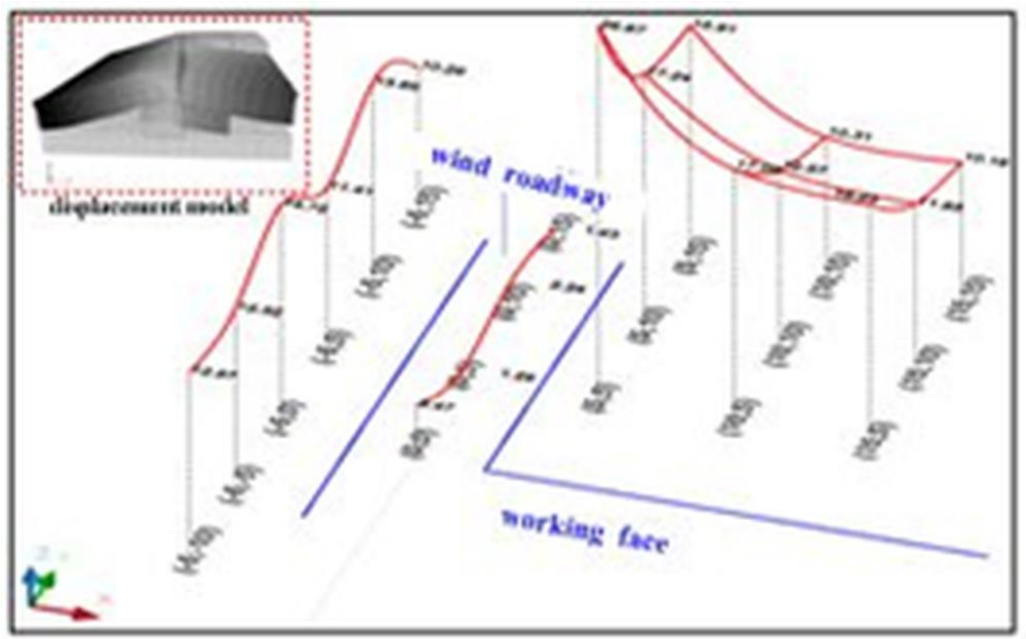

Fig. 8. Stress distribution of $3 \#$ headstock

(2) No. 2 and 3 \# headstock

The displacement of the top plate in the tip region and the vertical stress distribution is shown in Figure 9. A "masonry beam" hinge structure is formed on the basic roof, and the broken block rotates along with the hinge point. Stress concentration occurs in the top coal to some extent, and the highest stress concentration is located within $5 \mathrm{~m}$ of the solid coal side of the working face and the corner of the return air lane. The value of the concentration factor is 2.24 and the maximum displacement of the roof at the corner is $0.087 \mathrm{~m}$.

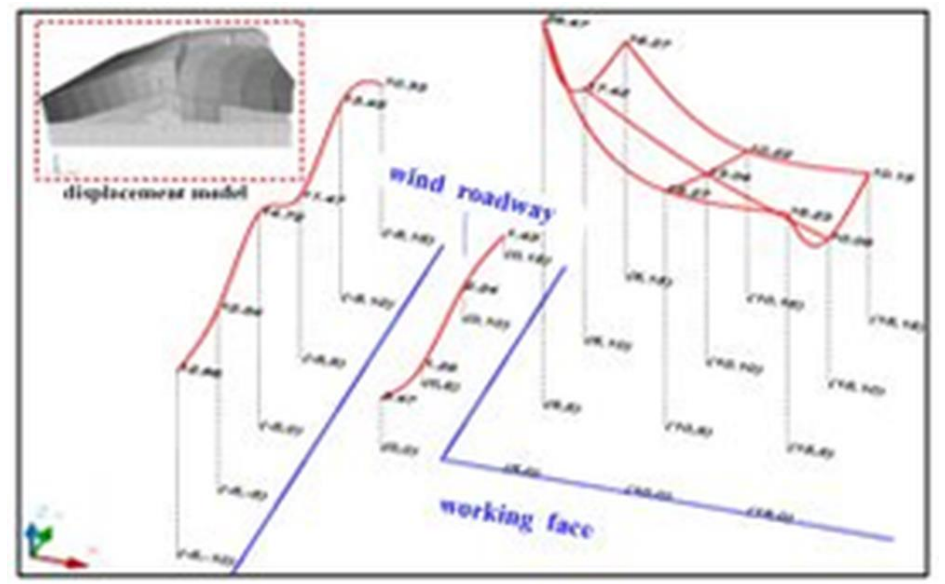

Fig. 9. Stress distribution of 2 and $3 \#$ headstock

(3) No. 1, 2 and 3 \# headstock

The displacement of the top plate in the tip area and the vertical stress distribution are shown in Figure 10. A "masonry beam" hinge structure is formed on the basic roof, and the broken block rotates along the hinge point. Stress concentration occurs in the top coal to some extent, and the highest stress concentration is located within $5 \mathrm{~m}$ of the solid coal side of the working face and the corner of the return air lane. The value of the concentration factor is 2.17 , and the maximum displacement of the roof at the corner is $0.087 \mathrm{~m}$. 


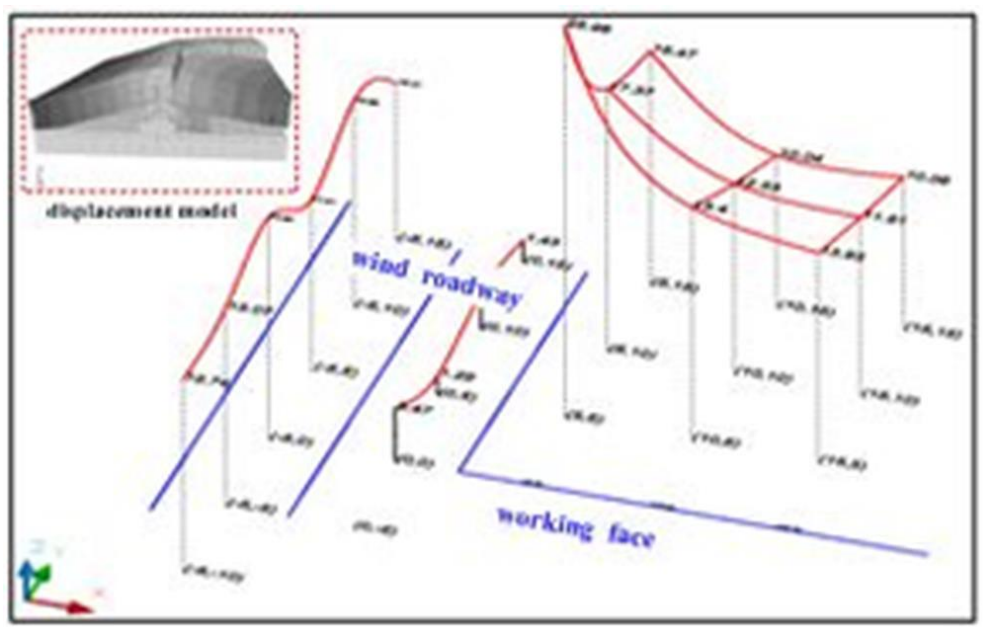

Fig. 10. Stress distribution of 1,2 and $3 \#$ headstock

\subsubsection{Impact of tailstock placement on the tip area}

(1) No. 3 \# tailstock

After the stock of the working face can cave coal normally, the 3 \# tailstock is tested. The numerical simulation results are shown in Figure 11. An "arch-like" hinge structure is formed on the basic roof, and the broken block rotates along the hinge point; a certain degree of stress concentration occurs in the top coal, and the highest concentration of stress is located within $5 \mathrm{~m}$ of the solid coal in the working face and the corner of the return air lane. The coefficient is 3.29; the maximum displacement of the roof at the corner is $1.08 \mathrm{~m}$.

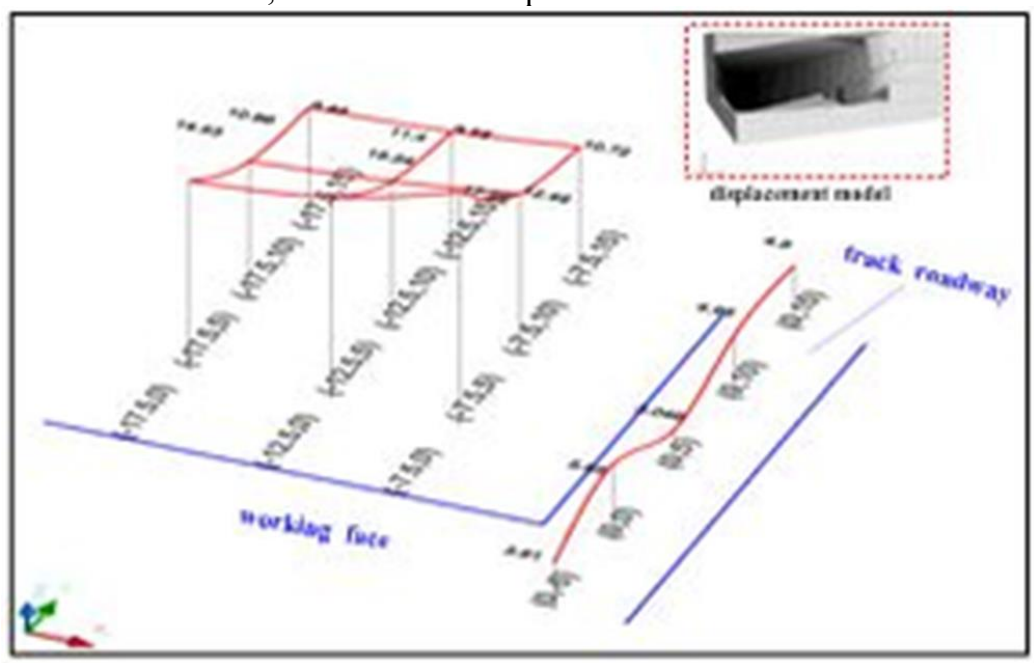

Fig. 11. Stress distribution of $3 \#$ tailstock

(2) No. 2 and 3 \# tailstock

The vertical stress distribution in the top coal at the end zone and the change in roof displacement are shown in Figure 12. A "arch-like" hinge structure is formed on the basic roof, and the broken block rotates along the hinge point; a certain degree of stress concentration occurs in the top coal, and the highest degree of stress concentration is located within $5 \mathrm{~m}$ of the solid coal side of the working face and the corner of the return air 
lane. The coefficient is 3.53 ; the maximum displacement of the roof at the corner is $1.23 \mathrm{~m}$.

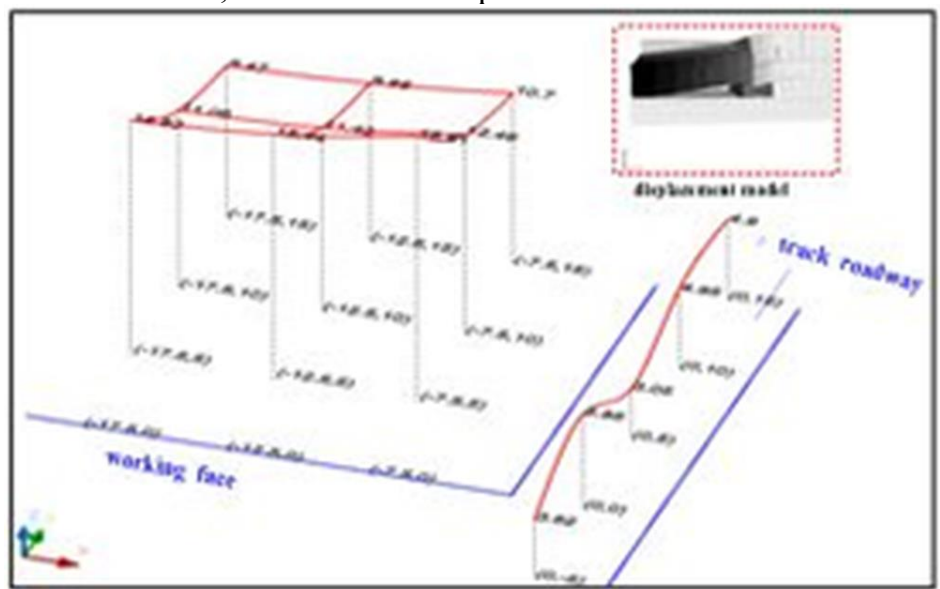

Fig. 12. Stress distribution of 2 and $3 \#$ tailstock

(2) No. 1, 2 and 3 \# tailstock

The distribution of vertical stress in the top coal at the end zone and the change in roof displacement are shown in Figure 13. A "arch-like" hinge structure is formed on the basic roof, and the broken block rotates along the hinge point; a certain degree of stress concentration occurs in the top coal, and the highest degree of stress concentration is located within $5 \mathrm{~m}$ of the solid coal side of the working face and the corner of the return air lane. The coefficient is 3.46; the maximum displacement of the roof at the corner is $1.26 \mathrm{~m}$.

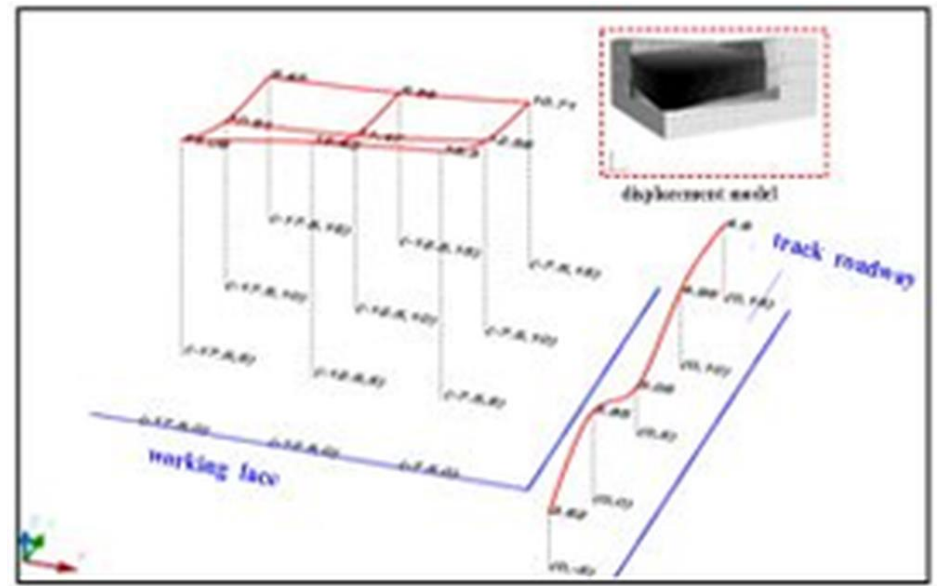

Fig. 13. Stress distribution of 1,2 and 3\# tailstock

\subsection{Comparison between top coal caving and non-caving of the stock}

According to the numerical simulation results of the above tests, without coal caving, No.3 \# tailstock caving coal, No .2 \#. tailstock caving coal, and No.1 \# tailstock caving coal, it can be seen that the influence of end caving on the movement of the old roof is little. The structure formed by the old top fault is basically the same, but specific the movement and displacement of the top coal are different. When the tailstock is not caving coal, the maximum displacement of the roof between the working face and the return airway is $1018.7 \mathrm{~mm}$, and the maximum pressure near the end is $23.3 \mathrm{MPa}$; when the 3 \# tailstock is 
caving coal, between the work surface and the return airway the maximum displacement of the roof at the cross position is $1082.2 \mathrm{~mm}$, and the maximum pressure of the end vicinity is $24.67 \mathrm{MPa}$; when the 2 \# and 3 \# tailstocks are both caving coal, the displacement of the roof at the position is $1231.9 \mathrm{~mm}$, and the maximum pressure of the end vicinity is 26.47MPa; when all the 1 \#, 2 \#, and 3 \# tailstocks caving coal, the displacement of the top plate at this position is $1263.9 \mathrm{~mm}$, and the maximum pressure near the end is $25.96 \mathrm{MPa}$.

After the tailstock caving the coal, the displacement of the roof at the intersection between the working face and the return airway increased by $6.23 \%, 20.93 \%$, and $24.07 \%$, respectively, and the peak pressure increased by $5.88 \%, 13.61 \%$, and $11.42 \%$, respectively. At the same time, according to the monitoring results of measuring points arranged in the coal pillars of the section, the maximum value of sinking of the coal pillars of the end vicinity is $360 \mathrm{~mm}$ when the tailing rack is not used for coal placement, and after all the tailstocks are used for the top coal the sinking distance is $367.56 \mathrm{~mm}$, an increase of $2.1 \%$. According to the results of the above numerical simulations, after tail stock caving coal, the pressure at the tip end increases by $13.61 \%$, the displacement of the roof increases by $24.07 \%$, and the displacement within the coal pillar increases by only $2.1 \%$. Within the control range, so the feasibility of coal discharge by tailstock is high.

According to the simulation results whether the stock caving coal, the roof displacement has little change. While not caving the coal, the displacement of the top plate at the position, the intersection between the transportation lane and the working surface, is $86.60 \mathrm{~mm}$. And the maximum pressure of the end vicinity is $17.99 \mathrm{MPa}$. After the 3 \# headstock caving the coal, the displacement of the top plate at this position is $86.83 \mathrm{~mm}$, and the maximum pressure near the end is $17.61 \mathrm{MPa}$. After the headstocks of 2 \# and 3 \# caving coal, the maximum displacement at this position is $88.54 \mathrm{~mm}$, and the maximum pressure near the end is $16.81 \mathrm{MPa}$. After the headstocks of 1 \#, 2 \# and 3 \# caving the coal, the maximum displacement at this position is $92.09 \mathrm{~mm}$, and the maximum pressure near the tip is $16.30 \mathrm{MPa}$. According to the results of the above numerical simulations, the displacements of the roof at the intersections between the working face and the return air lane of the three headstock caving coal schemes increased by $0.26 \%, 2.24 \%$, and $6.34 \%$ respectively. Compared to the coalless scheme, and the maximum pressures increased respectively. It is $2.11 \%, 6.56 \%$ and $9.39 \%$, which are all under the control.

After the top coal is caving, the value of roof sinking at the end vicinity of the return air is increased, but the maximum pressure at the measuring point is reduced. Based on this, it can be seen that the coal body near the working face is broken after the caving coal. And the peak of the supporting pressure inside the coal body is transferred to the inside of the coal body. According to the results of the above numerical simulations, the feasibility of coal placement at the transitional frames at both ends of the working face is relatively high, and it does not cause large roof subsidence and pressure increase.

\subsection{Monitoring scheme}

To study the distribution law of the mine pressure when caving coal at the end of No. 6202 working face, pressure gauges are installed on the headstocks of the working face 1 \#, 3 \# and the tailstocks of the working face of $1 \#, 2$ respectively, to monitor the pressure changes of the support when the coal is caving at the end or not during the advancing process of 6202 working face, which can compare and analyze the various characteristics of support pressure under the two conditions. The measurement point arrangement is shown in Figure 3. During the entire monitoring process, the working face is pushed for $60 \mathrm{~m}$ in total, and the first $30 \mathrm{~m}$ is pushed mining without caving coal at the end, while the last $30 \mathrm{~m}$ is pushed mining with caving coal at the end. Due to the cycle of the working face is about $10 \mathrm{~m}$. Therefore, it is not affected by the part that does not put coal at the end during the $30 \mathrm{~m}$ push-mining process. 


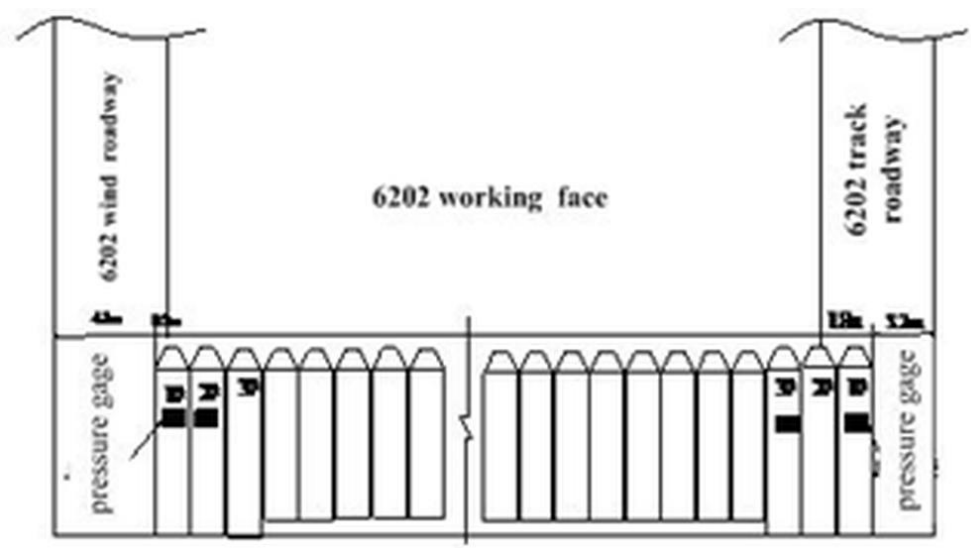

Fig. 14. Monitoring scheme of the end roof support pressure

\section{In-situ monitoring results and analysis}

According to the monitoring data, the pressure change curve of the head and tail rack is drawn. The pressure value of the headstock in the observation range is shown in Figure 15 and the pressure value of the tailstock in the observation range is shown in Figures 16. By comparing the curve of pressure at the end of the working face with caving coal or not, this paper finds the difference of the force on the transition frame:

(1) Whether the end of the working face is caving coal, the cycle of pressure change of the transition frame is basically the same, which is about $10 \mathrm{~m}$. Coal caving at the end and the head has little effect on the step size.

(2) When caving the coal at the end, the pressure of the transition frame is generally higher than that while not caving coal, and the curve of the push mining distance of the last $30 \mathrm{~m}$ clearly shows an upward trend, and the pressure peak is increased compared to while not caving the coal.

(3) It is found in Fig. 15 and Fig. 16 that when the end of the working face is not caving coal within the first $30 \mathrm{~m}$ distance, the pressure value of the tail end transition frame is higher than that of the head end transition frame. The pressure change of the head transition frame is more obvious than that of the tail transition frame while the end of the working face is caving coal within the last $30 \mathrm{~m}$ distance.

Whether caving coal, the difference of the transition frame between the roof at the working face is not only shown the change in the pressure value. After caving coal at the end, the increase in the pressure at the end of the roof can cause aggravation of pressure appearance. Through on-site monitoring, after caving coal at the end, the roof mine pressure at the end part appears to be stronger than while not caving the coal. This is mainly reflected in the following three points. First, according to the sound of the roof on-site, the extent of roof cracking can be judged. The louder it gets, the more the roof cracks. Secondly, the part of the end part close to the solid coal side of the working face appears the phenomenon of chipping. Thirdly, the deformation of the roadway at the intersection of the trough and the working face is more serious.

By analyzing the monitoring data and the characteristics of the mine pressure during the monitoring process, the following rules are summarized:

(1) The headstock is pushed forward within $60 \mathrm{~m}$ of the working face. The top of the head is pressed five times. The maximum stepping distance is $12.8 \mathrm{~m}$, the minimum stepping is $8.0 \mathrm{~m}$, and the average is $10.08 \mathrm{~m}$. The tailstock is within the observation range. The top end of the head is pressed five times, which is basically synchronized with the top 
of the headstock. The maximum step is $13.6 \mathrm{~m}$, the minimum is $8.0 \mathrm{~m}$, and the average is $10.20 \mathrm{~m}$.

(2) Whether caving coal, the stepping distance of the top is basically the same, with an average of $10 \mathrm{~m}$. The end coaling has little effect on the stepping distance.

(3) The tailgate monitoring pressure value is significantly greater than the headstock pressure value, that is, the pressure at the end of the return wind downslot is larger. It is due to the return wind downslot approaching the 6216 goaf.

(4) The pressure of the support is generally higher when caving the coal at the end than when not caving the coal, and there is a clear upward trend in the last $30 \mathrm{~m}$ of the curve.

(5) The pressure of the mine after the end of coal mining is more severe than when the coal is not coal mining, which is mainly manifested in the serious deformation of the roadway in the end zone and the coal wall.

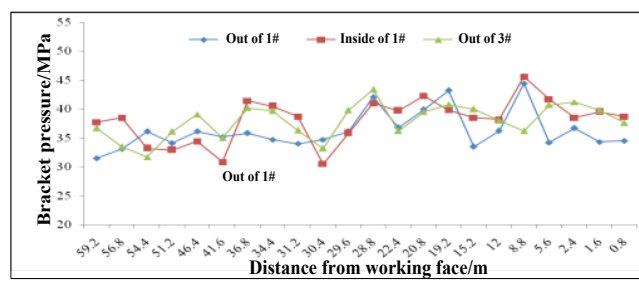

(a) Monitoring results

Fig. 15. Pressure curve of headstock

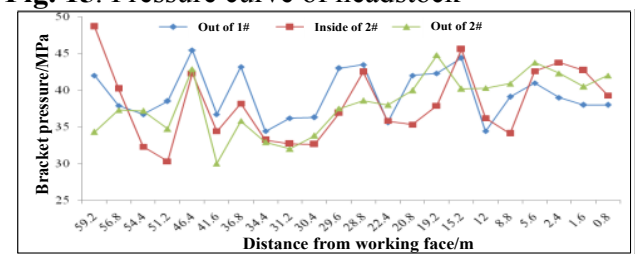

(b) Average
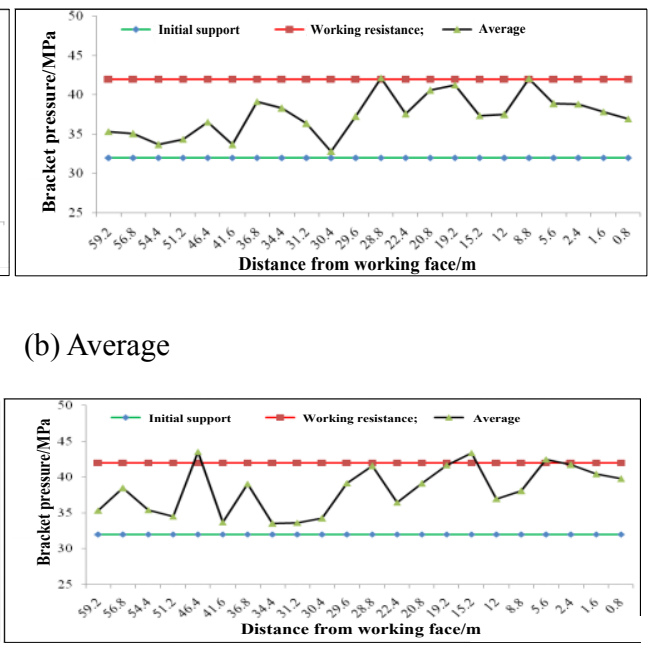

(a) Monitoring results

(b) Average

Fig. 16. Pressure curve of tailstock

\section{Conclusions}

Using 3DEC software and on-site monitoring, the roof pressure and movement of the top coal are studied, and the following main conclusions are drawn:

(1) When caving the coal at the end or not, the basic top structure of the end is basically same. Due to the existence of the coal pillars at the end of the return airway, the roof forms an "arch-like" hinge structure. The rotational sinking occurred, the roof structure at the end of the transport lane forms a typical "masonry beam" structure. In the process of simulating the sequential discharging of the tailstock, the peak pressure of the mine in the coal is $26.47 \mathrm{MPa}$ and the stress concentration factor is 3.53 . Compared with the tailstock, there is $26.29 \mathrm{MPa}$ during coal discharge, the pressure in front of the coal wall at the working face is basically unchanged.

(2) During the simulation of sub-sequential coal discharge, the peak pressure of the support in the coal body is $17.61 \mathrm{MPa}$, and the stress concentration factors is 2.35 . During caving coal, the pressure in front of the coal wall at the working face does not increase much. And the pressure value tends to decrease with the increase of the coal support, which indicates that the supporting pressure is transferred to the front of the working face with the 
caving of the top coal of the transition frame. So the end of the coal wall can not bear too much force, the coal body support should be strengthened in the working face.

(3) The measurement points arranged in the return lane show that the pressure value gradually decreases until it stabilizes behind the working face, but the pressure value fluctuates up and down in the advancing direction of the working face, with a period of about $10 \mathrm{~m}$, indicating the trough top plate is within the top plate collapse line of the upper section. The stepping pressure of the roof is basically the same whether caving coal at the end, with an average of $10 \mathrm{~m}$. The tipping coal has little effect on the stepping pressure; the support pressure is generally less than that when the terminal is coaled.

\section{References}

1. Y. Chen, S.Q. Ma, Y. Yu, Rock Eng., 50, 9, 2511 (2017)

2. S.M. Chen, A.X. Wu, Y.M. Wang, X. Chen, R. F.Yan, H. J.Ma, Eng. Failure Anal., 92, 443 (2018)

3. G.R. Feng, P.F. Wang, P.C. Yoginder, Rock Mech. Rock Eng. 52, 8, 2741 (2019)

4. X.F. Guo, Z.Q. Zhao, X. Gao, X.Y. Wu, N.J. Ma, Int. J. Min. Sci. Technol, 29, 2, 263 (2019)

5. M.C. He, Eng. Geol., 121, 165 (2011)

6. B.K. Hebblewhite, T. Lu, Int. J. Rock Mech. Min. Sci., 41, 1, 147 (2004)

7. L.S. Jiang, A. Sainokic, H.S. Mitri, N.J. Ma, H.T. Liu, Z. Hao, Int. J. Rock Mech. Min. Sci., 88, 307 (2016)

8. Y.Y. Jiao, L. Song, X.Z. Wang, C.A. Amoussou, Int. J. Rock Mech. Min. Sci., 60, 19 (2013)

9. S.C. Li, Q. Wang, H.T. Wang, B. Jiang, D.C. Wang, B. Zhang, Y. Li, G.Q. Ruan, Tunn. Undergr. Space Technol., 47, 52 (2015)

10. Z.Q. Ma, Y.D. Jiang, W.S. Du, Y.J. Zuo, D.Z. Kong, Eng. Failure Anal., 84, 331 (2018)

11. R. Pan, Q. Wang, B. Jiang, S.C. Li, H.B. Sun, Q. Qin, H.C. Yu, W. Lu, Eng. Failure Anal., 80, 218 (2017)

12. S. Shnorhokian, B. MacNeil, H.S. Mitri, J. Rock Mech. Geotech. Eng., 10, 1, 60 (2018)

13. R. Singh, Int. J. Rock Mech. Min. Sci., 41, 5, 745 (2004)

14. B., Unver, N.E., Yasitli, Int. J. Coal Geol., 66, 4, 227 (2006)

15. J.H. Wang, B. Yu, H.P. Kang, G.F. Wang, D.B. Mao, Y.T. Liang, P.F. Jiang, Int. J. Coal Sci. Technol., 2, 2, 97 (2015)

16. J.C. Wang, Z.H. Wang, Int. J. Min. Sci. Technol., 29, 1, 65 (2019)

17. H.P. Xie, J.H. Wang, B.H. Shen, J.Z. Liu, P.F. Jiang, H.W. Zhou, H. Liu, G. Wu, J. China Coal Soc., 37, 7, 1069 (2012)

18. S.R. Xie, M.M. Gao, D.D. Chen, Y.D. Sun, H. Pan, H. Su, S.Z. Lan, Int. J. Min. Sci. Technol., 28, 3, 445 (2018)

19. B. Yu, R. Gao, T.J. Kuang, B.J. Huo, X.B. Meng, Tunn. Undergr. Space Technol., 86, $156(2019)$

20. H. Yan, F.L. He, L.Y. Li, R.M. Feng, P.F. Xing, J. Cent. South Univ., 24, 5, 1098 (2017)

21. C.W. Zang, M. Chen, G.C. Zhang, K. Wang, D.D. Gu, Energy Sci. Eng., 00, 1 (2020) 